\title{
Research on the Development Mode of Ice and Snow Sports Industry in Heilongjiang Province
}

\author{
Ma Baofa, Zhang YuanFeng \\ Heihe University School of Physical Education, Heihe, Heilongjiang, 164300
}

Keywords: Ice and snow sports industry; Heilongjiang Province; Development mode

\begin{abstract}
Ice and snow sports culture is a valuable treasure that nature has given to Heilongjiang Province. Through the study of a large number of literatures, the comprehensive discussion is conducted by the method of theoretical analysis, which indicates that Heilongjiang Province should seize the good opportunity of holding the Winter Universiade in Harbin which is known as the ice city and enhance the business model of the ice and snow sports industry at the present according to the existing policies. The existing problems in the development process at the present stage is summarized and the corresponding solutions are proposed. At the same time, the bid for the ice and snow events is strengthened.
\end{abstract}

The ice and snow industry in Heilongjiang Province showed a sustained expansion trend during the Tenth Five-Year Plan period from 2001 to 2005. The per capita gross domestic product exceeded more than 1,700 US dollars, driving the whole tourism industry in Heilongjiang Province, and increasing the number of tourists and the income of ice and snow tourism rapidly. Heilongjiang has completed the perfect transformation of province with ice and snow economy from the province of ice and snow resources. Some policy documents related to sports industry of China was found through consulting a large number of documents, and used theoretical analysis and other research methods to study the current situation of ice and snow sports industry of China. The reform of the system and policy of the sports industry has been adjusted and implemented gradually by the state. All provinces, municipalities and autonomous regions have a general understanding of the role and contribution of the sports industry to the social and economic development. Industrial structure, investment and consumption structure of Heilongjiang Province will also change during this period. Therefore, higher and newer requirements are put forward for how the ice and snow sports industry will develop better in the future.

\section{Development mode of sports industry}

At present, the development mode of sports industry in China is relatively good. Shanghai, an economically powerful city, has spent nearly 6 billion yuan on the construction of competition venues and corresponding infrastructure by taking advantage of the good opportunity of the World Automobile Grand Prix held in Shanghai. catering industry of Shanghai, transportation industry, tourism industry and real estate industry have been driven positively, and achieved considerable benefits. Changchun has enhanced its competitiveness on the international platform and also promoted the development of the city's sports industry through some international events held in the city over the years.

The European sports industry developed as early as 1608. It started with the creation of golf clubs. Good training grounds and facilities for matches were built because of this club. As a result, sports events and crowds were brought in and different sports clubs were formed. Clubs consist of individuals with the same hobbies, ideas and interests, and develop into national sports social organizations gradually. These organizations form international federations through improvement and integration. They can coordinate and organize national competitions themselves without the need for national money. Countries and governments are beginning to rely on these sports organizations to play some role as development gets better and better.

The ice and snow industry in Heilongjiang Province was developed gradually in 1996 when the 
Asian Winter Games were held. The provincial government also invested a lot of money to support it. At the same time, through the related construction of large-scale competitions, it led to the development of related industries and undertakings, such as ski resorts, tourist villas, transportation, catering and service industries and so on. The management of ice and snow sports industry in Heilongjiang Province tended to be industrialized in the past. The management mode will be changed in the future. The government will give priority to the investment of sports events, and more investment will be used to develop the ice and snow sports industry, which will be transformed into the mode of enterprise operation and management.

\section{Future development strategies and models of the ice and snow sports industry in Heilongjiang Province}

The ice and snow industry in Heilongjiang Province should establish a correct idea of win-win in future industrial development, strengthen the strategic cooperation consensus among the cities constantly, and give full play to the coordination and organization mechanism of the relevant administrative departments of provincial and municipal governments to the ice and snow industry. The development direction of sports industry with different characteristics should be formed according to the different cultural characteristics of different regions, to avoid vicious, disorderly industrial competition and repetitive facilities construction among different regions. Cooperation with foreign ice and snow sports industry ought to be strengthened, as well as cooperation with domestic provinces and cities with developed sports industry to learn their industrial management experience and technology and introduce the necessary funds for industrial development. It is also necessary to make up for the shortage of funds for the construction of ice and snow sports industry in Heilongjiang Province and the shortage of core competitiveness and slightly lower service quality. The management level of ice and snow sports industry must be improved in order to promote the healthy and rapid development of ice and snow sports industry in the direction of international marketization.

Heilongjiang Province can follow the example of some developed countries in Europe, set up its own ice and snow sports club, promote the development of the professionalization of ice and snow sports in Heilongjiang Province, and make the economic benefits of the snow sports industry in the province through the operation of the club management personnel on the commercialization of related events. Promote the market-oriented communication and exchange of club members so that their sense of competition and vocational and technical level can be upgraded, and the development of ice and snow sports industry in Heilongjiang Province can be promoted.

Heilongjiang Province can seize the good opportunity of industrial and commercial development by holding the "Winter Universiade", build the scale of ice and snow sports industry in actively, and do a good job of propaganda, so that some domestic and even international competitions can be held in Heilongjiang Province every year. It is also possible to refer to some developed countries in Europe, strive to develop ice and snow sports clubs, conduct domestic and international leagues, and make the ice and snow sports industry and related enterprises and industries in Heilongjiang Province developed better.

The number of people watching the ice events is very small compared with the snow events in Heilongjiang, and the market is bleak. For example, tickets for a world-class ice competition have been reduced to 20 yuan, but the audience is very small. Television and the media had to mobilize some college students and high school students to act as spectators when the competition entered the final stage, in order to broadcast the scene in a good atmosphere. But the ski market is very prosperous, the outdoor temperature is very low in the Northeast winter, but people would rather endure the winter bleak in order to watch skiing competitions, and the audience is very large. In terms of propaganda, the promotion of ice events and snow events is also very different. The promotion of ice events can only be seen near the stadium. However, the advertisements of snow events can be seen in bus stops, subway stations, LED propaganda screens of large buildings, and large billboards. In this regard, Heilongjiang Province should coordinate the healthy and rapid development of the entertainment industry and the competitive industry. 
It is suggested that schools, enterprises and institutions should build their own skating rinks and ice hockey rinks to facilitate students and workers to exercise. Harbin Municipal Government allows the use of idle land and river courses with high safety factor to develop sports venues in winter. This policy not only promotes the development of ice and snow sports industry in the province, but also enhances the enthusiasm of the masses and tourists for ice and snow sports. It is suggested that Harbin Municipal Government install some lighting equipment in the ice and snow sports venues, so that it is more convenient for ice and snow sports enthusiasts to exercise at night.

The industry should have advanced management concepts and theoretical knowledge if the ice and snow sports industry in Heilongjiang Province wants to develop more quickly and orderly in the future, and operators and managers should have a certain understanding of the service level of the industry. It is necessary to strengthen the personnel training and echelon construction of sports operators in order to strengthen the construction of ice and snow sports industry, so that the managers can understand the relationship and difference between ice and snow sports industry and tourism clearly, play the role of ice and snow sports industry better, and make ice and snow sports industry become an industry that can be sustainable development in the future. It will promote economic efficiency and upgrade the sports industry in the whole province.

\section{Conclusion}

Operators and managers of ice and snow sports industry in Heilongjiang Province should draw lessons from the development process over the years, determine the future development direction and trend of ice and snow industry correctly, formulate corresponding implementation strategies, improve the core competitiveness of ice and snow sports industry at home and abroad, and make it develop healthily, orderly, and rapidly.

\section{Acknowledgement}

Fountain of program: The annual project of Heilongjiang Philosophy and Social Science Research Program (Physical Education and Training)

Project name: The Construction of Business Models of the Ice Snow Sport Industry in Heilongjiang Province

Project number: 18TYE555

\section{References}

[1] Li Hongbin, Zhu Cheng. Some Thoughts on the Development of Ice and Snow Sports Industry in Heilongjiang Province [J]. Ice and Snow Sports, 2005, (03): 77-78.

[2] Zhang Liangxiang, Yi Zhiqiang, Wu Wei, et al. [J] Journal of Qiqihar University (Natural Science Edition), 2007, 23 (03): 88-91.

[3] Tang Baosheng. Humanistic Value of Ice and Snow Sports Education [J] Ice and Snow Sports, 2010, 32 (02): 70-73.

[4] Zhang Yang. Niche Strategy for the Development of Ice and Snow Sports Industry [J] Ice and Snow Sports, 2010, 32 (06): 92-96. 